\title{
PAIDEIA Y
}

HUMANITAS: EN EL PASADO, LAS RAÍCES DEL FUTURO*

\author{
Giovanni Reale**
}

\begin{abstract}
Partimos de una hermosa observación
de Arnold Gehlen contenida en su célebre libro El hombre, su naturaleza y su lugar en el mundo, que a menudo cito, porque es emblemática:
\end{abstract}

Hay un ser vivo que entre sus características más relevantes tiene la de tener que tomar posiciones sobre sí mismo, para lo que es necesario, precisamente, una 'imagen', una fórmula interpretativa. 'Sobre sí mismo’ significa acerca de las propias pulsiones y cualidades percibidas, pero también acerca de sus semejantes, los otros hombres. En efecto, también el modo de tratar a los hombres depende de cómo se les considera y de cómo se considera uno a sí mismo. Pero esto quiere decir que el hombre debe interpretar su naturaleza y por eso asumir un comportamiento activo capaz de tomar posición respecto a sí mismo y respecto a los otros, lo que no es tan fácil de hacer. ${ }^{1}$

* Texto presentado en el Congreso Internacional Paideia e Humanitas, Roma, 2000. Traducción del italiano de María Luisa Ibañez y Palecha.

** Profesor Ordinario de Historia de la Filosofía Antigua en la Universidad Católica del Sagrado Corazón de Milán.

${ }^{1}$ A. Gehlen, Der Mensch. Seine Natur und seine Stllung in der Welt, 1978, Wiesbaden, edición italiana, 1990², Milán, Feltrinelli, p. 35. 


\section{GIOVANNI REALE}

Pero ¿por cuál motivo resulta tan difícil para el hombre comprenderse y representarse?

La razón es ésta: el hombre posee una realidad muy compleja que, según la perspectiva desde la que se la mira, se interpreta de maneras diferentes e, incluso, entre ellas en neta antítesis.

Efectivamente, la naturaleza del hombre resulta ser ontológicamente ‘intermedia’ entre el animal y algo que va más allá del animal. Bien podemos entender, por tanto, cómo, según la perspectiva desde la que se mira, el hombre aparezca como un ente de extraordinaria grandeza (imagen de Dios) o bien lo opuesto, de extraordinaria pequeñez (un animal inferior al común animal, en cuanto aún incompleto, mientras que el animal es completo).

De todas maneras hay que precisar que todas las imágenes filosóficas del hombre propuestas a lo largo de los siglos se remontan a la creada por los griegos, de quienes tenemos que hablar. Y, por consiguiente, también las varias concepciones de la paideia, o sea de la educación y de la formación del hombre, tienen raíces exquisitamente helénicas.

Pero inmediatamente hay que decir que, si acerca de esto se ha logrado desde hace tiempo un acuerdo de opiniones en general, sólo durante la segunda mitad del siglo Xx han sido tomados y explicados algunos puntos-clave, que permiten comprender la cuestión en su compleja articulación y, por tanto, en su justa dimensión y en su preciso alcance. ${ }^{2}$

Los griegos presentaron al hombre en la doble dimensión de soma y de psyché (cuerpo y alma), y desde el Medioevo hasta hoy han permanecido como referencia estas connotaciones ontológicas esenciales si bien con interpretaciones muy diferentes y, a menudo, opuestas. Quiero decir que han sido sucesivamente entendidos de manera muy diversa y también antitética tanto el soma como la psyché.

Hagamos alguna aclaración preliminar.

${ }^{2}$ Muchas de las ideas que sostengo aquí han sido extraídas de mi primer libro Corpo, anima e salute. Il concetto di uomo da Omero a Platone, Cortina, Milán, 1999, así como de mi monografía, Socrate. Alla ricerca della sapienza umana, 2000, Milán, Rizzoli. 
Se debe recordar, en primer lugar, que la concepción del hombre como soma y psyché, en aquel sentido que ha resultado determinante en la historia espiritual de Occidente, se remonta al siglo quinto a.C.

Durante mucho tiempo no se ha entendido que estos términos soma y psyché, que aparecen ya en la Ilíada y en la Odisea, en la concepción homérica tiene significados completamente diversos de los que han asumido a partir, precisamente, del siglo quinto a.C.: soma significaba el cadáver, el muerto; psyché quería decir lo que hoy llamaríamos fantasma, o sea, la sombra espectral que se va al Hades, privado de conciencia y de capacidad de obrar: representaba la vida que se ha ido y que ya no está, y que W. Otto ha definido bien como representación de 'un haber sido', o sea como el 'ser del haber sido'. 3

La idea de alma como algo de divino en el hombre nació con la aparición y la difusión del Orfismo, por un lado, y, después, mediante el pensamiento de algunos filósofos presocráticos y, sobre todo, por obra de Sócrates, con la imponente fundación metafísica y los desarrollos de la misma realizados por Platón.

A los órficos se remonta la idea de que el verdadero hombre es aquel demonio-alma puesto en un cuerpo mortal para pagar una culpa originariamente cometida, y de la cual debe purificarse para regresar pronto junto a los dioses.

La fórmula más significativa contenida en laminillas de oro encontradas en las tumbas de seguidores del Orfismo decía así:

De hombre renacerás dios, porque tu origen es divino.

Sin embargo los órficos no sólo separaban netamente la inteligencia y la conciencia del demonio-alma, sino que la presentaban en contraposición, en cuanto retenían que el demonio-alma aparecía en los momentos de inconsciencia, de desmayos y, por tanto, con la muerte. ${ }^{4}$

${ }^{3}$ Cfr. Reale, Corpo, anima e salute, p. 15-89. La obra de W. Otto que contiene la expresión citada es: Theophania. Der Geist der altgriechischen Religion, 1975, Frankfurt a.M.; edición italiana, 1983, Il Melangolo, Génova.

${ }^{4}$ Cfr. Reale, Corpo, anima e salute, op. cit., p. 129-40. 


\section{GIOVANNI REALE}

El nexo entre la psyché y la inteligencia y la conciencia nace ya con los filósofos naturalistas, en forma embrionaria y a nivel intuitivo, ${ }^{5} \mathrm{y}$ alcanza un vértice de altura asombrosa con Heráclito en el fragmento que sigue:

Los confines de la psyché no los podrás alcanzar nunca, por más que tú llegues hasta el fondo recorriendo sus vías: tan profundo es su logos. ${ }^{6}$

Bruno Snell ha sido el primer estudioso que ha puesto en evidencia el alcance revolucionario de tal fragmento, en cuanto invierte el lenguaje y el modo de pensar homérico. Escribe Snell:

Para nosotros esta concepción de la profundidad del alma es algo común, y hay en ella algo de totalmente extraño a un órgano físico y a su función. Decir que alguien tiene una mano profunda, una oreja profunda, no tiene sentido. (...) La representación de la profundidad ha aparecido precisamente para designar la característica del alma, que es la de tener una cualidad particular que no se refiere ni al espacio ni a la extensión, aunque estemos obligados a usar una imagen espacial para designar esta cualidad sin espacio. Con ella Heráclito quiere significar que el alma se extiende al infinito, exactamente lo contrario de lo que es físico. ${ }^{7}$

Algunos estudiosos han resaltado también algunos fragmentos de Demócrito, como por ejemplo, éstos:

${ }^{5}$ Ibid., p. 141-54.

${ }^{6}$ Heráclito, fr. 45 DK.

${ }^{7}$ B. Snell, Die Entdeckung des Geistes. Studien zur Entsebung des europäische Denkens bei den Griechen, 1946, Hamburgo; edición italiana con el título La cultura greca e le origini del pensiero europeo, 1963, Turín, Einaudi, p. 40 s. 
Quien elige los bienes del alma escoge realidades más divinas, mientras que quien opta por los bienes del cuerpo, escoge realidades más humanas. ${ }^{8}$

La felicidad no consiste en la posesión del ganado ni tampoco del oro: es el alma la morada del demonio que nos ha tocado en suerte. ${ }^{9}$

A los hombres conviene considerar más el alma que el cuerpo, ya que la perfección de la primera pone remedio al mal estado del segundo, mientras que la fuerza del cuerpo no aporta ninguna mejora al alma si no está acompañada por la capacidad de razonar. $^{10}$

Mas, a pesar de la belleza y profundidad de tales pensamientos, éstos no resultan ser históricamente determinantes, ya que Demócrito nació el 460 a.C., o sea aproximadamente diez años después de Sócrates (nacido el 470/469 a.C.) y murió muy viejo, mucho después que Sócrates.

Por parte de muchos estudiosos ya está confirmada la tesis según la cual fue el propio Sócrates, si no el creador absoluto, por lo menos quien sostuvo de modo sistemático la identificación de la psyché con la personalidad intelectual y moral del hombre, e impuso dicha tesis en la cultura griega con su dialéctica y su retórica de la persuasión.

La famosa frase que Apolo dirige al hombre, esculpida en la entrada del templo de Delfos, ‘conócete a ti mismo', era interpretada por Sócrates de esta manera:

El hombre es diverso de su cuerpo (...); el alma nos ordena conocer al que manda 'conócete a ti mismo'.11

${ }^{8}$ Demócrito, fr. 37 DK.; tomada de Atomisti Antichi, Testimonianze e frammenti, curado por M. Andolfo, texto griego para comparar, 1999, Milano, Rusconi Libri.

${ }^{9}$ Demócrito, fr. 171 DK.

${ }^{10}$ Demócrito, fr. 187 DK.

${ }^{11}$ Platón, Alcibiade maggiore, 131 A (va leído todo el pasaje $121 \mathrm{E}-138^{\circ}$ ). 
GIOVANNI REALE

Por Xenofonte sabemos incluso que, conversando con escultores y pintores, Sócrates sostenía precisamente la tesis que para representar al hombre,

el artista debe representar, a través de la forma exterior, la actividad del alma. ${ }^{12}$

El paso que resume el gran mensaje de Sócrates -que constituye la base sobre la cual se ha construido la cultura occidental, y en la que se encuentran aquellas raíces de las que necesariamente deberá depender también el futuro- está contenido en la Apología de Sócrates de Platón, que -a diferencia de los otros diálogos- constituye un documento histórico incuestionable (si Platón no hubiera dicho la verdad sobre lo que Sócrates había dicho en su proceso, que era un proceso de Estado de máxima gravedad, habría sido merecedor él también de un proceso y de una condena).

Leámoslo por completo, porque constituye el fundamento del discurso que estamos haciendo:

Agradezco vuestro interés y os aprecio, atenienses, pero prefiero obedecer antes al dios que a vosotros y mientras tenga aliento y las fuerzas no me fallen, tened presente que no dejaré de inquietaros con mis interrogatorios y de discutir sobre todo lo que me interese, con cualquiera que me encuentre, a la usanza que ya os tengo acostumbrados, y aún añadiría: “Oh tú, hombre de Atenas y buen amigo, ciudadano de la polis más grande y de la más renombrada por su intelectualidad y su poderío, ¿no te avergüenzas de estar obsesionado por aumentar al máximo tus riquezas y con ello, tu fama y honores, y por el contrario descuidas las sabiduría y la grandeza de tu espíritu y cómo lograr engrandecerlas?

Y si alguno de vosotros me lo discute y presume de preocuparse por tales cosas, no le dejaré marchar, ni yo me alejaré de su

${ }^{12}$ Cfr. Xenofonte, Memorabili, III 10, 1-8. 
lado, sino que le someteré a mis preguntas y le examinare y si no me parece que está en posesión de la virtud, aunque afirme lo contrario, le haré reproches porque aquello que más estima merece, él lo valora en poco o en nada, en tanto que prefiere las cosas más viles y despreciables.

Éste será mi modo de obrar con todo aquel que se me cruce por nuestras calles, sea joven o mayor, forastero o ateniense, pero sobre todo con mis conciudadanos, por cuanto tenemos una sangre común (...).

En efecto, yo no tengo otra misión ni oficio que el ir deambulando por las calles para persuadir a jóvenes y ancianos de que no hay que inquietarse por el cuerpo ni por las riquezas, sino como ya os dije hace poco, por cómo conseguir que nuestro espíritu sea el mejor posible, insistiendo en que la virtud no viene de las riquezas, sino que las riquezas y el resto de bienes y la categoría de una persona vienen de la virtud que es la fuente de bienestar para uno mismo y para el bien público. $^{13}$

No es que Sócrates considerara ‘disvalores’ los que tradicionalmente eran considerados bienes por los griegos; consideraba, más bien, que no eran bienes en sí mismos y por sí mismos y que adquirían validez efectiva sólo si estaban unidos al conocimiento del bien y del mal, o sea si se ponían bajo el control de la razón, o sea del alma. El hombre no se construye aumentando lo que tiene -sus posesiones materialesni tampoco cultivando sólo los bienes conectados con el cuerpo, sino ocupándose de su psyché, o sea de lo que verdaderamente es.

De esta manera él realizaba una verdadera revolución cultural, de extraordinario alcance, invirtiendo las convicciones más antiguas.

En una famosa poesía, que se cantaba en los banquetes, los griegos ponían como punto de referencia la siguiente tabla de valores, que reproducimos en una traducción clásica:

${ }^{13}$ Platón, Apologia di Socrate, 29 B-30 D; traducción nuestra, publicada en edición separada y en Platone, Tutti gli scritti, 2000, Milán, Bompiani. 
GIOVANNI REALE

Estar sano es un bien supremo que nos ha sido dado: después viene del cuerpo tener belleza; sin engaños ser rico es el tercero, y después con los amigos gozar la juventud.

Por encima de todos estos valores ('salud', 'belleza', 'riqueza honrada’, 'juventud’), que están ligados principalmente a la dimensión de lo físico, con Sócrates se proponen, por lo tanto, los valores de la psyché, su areté, el conocimiento (del bien y del mal) y lo que éste comporta en la vida del hombre.

La tarea que el filósofo se había propuesto era precisamente la de exhortar a los hombres a preocuparse del alma, o sea al reconocimiento y a la conquista de estos nuevos valores de la psyché.

¿Existe alguna relación entre esta revolución de los valores con el cristianismo?

Hay quien lo ha negado y hay quien lo ha puesto más correctamente en evidencia según una óptica más justa.

El concepto de alma (psyché) ciertamente es una creación espiritual de los griegos; no se encuentra ad litteram en los textos evangélicos y ha sido el pensamiento teológico cristiano el que la ha absorbido y se la ha apropiado.

Pero hay que decir inmediatamente que resulta problemática la cuestión de la 'inmortalidad del alma' -consagrada por Platón- en comparación con la doctrina cristiana de la 'resurrección'. Es oportuno también precisar que Sócrates ha dejado el problema de la inmortalidad en suspenso: consideraba no ser capaz de demostrar la inmortalidad del alma racionalmente (sólo con las adquisiciones de carácter metafísico de Platón tal demostración se puede afrontar), pero la admitía en forma de esperanza y, por tanto, de fe. ${ }^{14}$

De cualquier manera vale la pena leer un fragmento de Oscar Cullmann, que ha presentado de modo drástico tal problema:

${ }^{14}$ Cfr. Reale, Socrate, p. 155-208. 
Se trata antes que nada de escuchar lo que dice Platón y lo que dice San Pablo. Se puede ir más allá. Se pueden respetar, es más, admirar, las dos enseñanzas. Y ¿cómo no hacerlo, sobre todo si se ponen en relación con la vida y la muerte de sus autores? Pero todavía no es una razón suficiente para negar que existe una diferencia radical entre la espera cristiana de la resurrección de los muertos y la creencia griega de la inmortalidad del alma. La admiración, por más sincera que sea, por las dos concepciones, no nos autorizaría jamás a pretender, contra nuestra convicción profunda o contra la evidencia exegética, que ellas son compatibles entre sí.

Que existan puntos de encuentro, Cullmann lo admite; pero niega la convergencia de inspiración, y escribe:

Si además el cristianismo ha establecido, más tarde, un vínculo entre las dos creencias y si el cristianismo medio las confunde hoy tranquilamente entre sí, ello no nos ha parecido razón suficiente para callar sobre un punto que, con la mayoría de los exégetas, consideramos la verdad; tanto más que la conexión establecida entre la 'resurrección de los muertos' y la creencia en la ‘inmortalidad del alma' en realidad no constituye siquiera un nexo, sino una renuncia a una a favor de la otra: se ha sacrificado al Fedón el capítulo 15 de la primera epístola a los Corintos. ${ }^{15}$

La cuestión planteada por Cullmann, de gran importancia, nos interesa en nuestra ponencia sólo marginalmente. De todas formas, he aquí, cómo Werner Jaeger da una respuesta medida y pertinente en dos bellos pasajes de su obra principal, Paideia:

${ }^{15}$ O. Cullmann, Immortalitá dell'anima o risurrezione dei morti?, 1967, ed. it., Brescia, Paideia, p. 9 s. 
GIOVANNI REALE

He aquí algo nuevo (...) que os ha traído el pensamiento de Sócrates: y es el mundo interior. La areté de la que habla es un valor propio del alma. Pero ¿qué es el alma o, con la palabra griega y socrática, qué es la psyché? Permítaseme, por el momento, proponer este problema en un sentido puramente filológico. Lo que sorprende es que cuando Sócrates, en Platón como en otros socráticos, pronuncia esta palabra 'alma' pone siempre en ella un acento muy fuerte y parece envolverla con un tono apasionado y urgente, casi de evocación. Labios griegos no habían pronunciado nunca así esta palabra, antes de él. Se tiene la sensación de algo que no es conocido por otra vía: y la verdad es que aquí, por primera vez en el mundo de la civilización occidental, se nos presenta lo que nosotros todavía hoy a veces llamamos con la misma palabra, a pesar de que los psicólogos modernos no le asocian la noción de sustancia real. La palabra 'alma', para nosotros, a causa de las corrientes espirituales por las que ha pasado a la historia, suena siempre con un acento ético o religioso; como otras palabras: 'servicio de Dios' y 'cuidado de almas' suena cristiana. Pero este alto significado, lo ha tomado por primera vez en la predicación exhortativa de Sócrates. Y, téngase en cuenta, que nosotros prescindimos aquí de la cuestión cuánto haya influido el concepto socrático de alma, inmediatamente o a través de la filosofía más tardía, sobre el cristianismo en sus diversas fases, o de hasta qué punto coincida con el concepto cristiano: lo que principalmente nos importa señalar es el cambio radical que el concepto socrático de alma representa dentro del desarrollo espiritual griego considerado en sí mismo. ${ }^{16}$

${ }^{16}$ W. Jaeger, Paideia. Die Formung des griechischen Menschen, 19361947, Berlín, 3 vol.; edición italiana: Paideia. La formazione dell'uomo greco, 1936-1959, Florencia, La Nuova Italia, reeditada varias veces; el pasaje citado se encuentra en el vol. II, $62 \mathrm{~s}$. 
Jaeger precisa ulteriormente:

Una forma como la del discurso exhortatorio de Sócrates no podía salir sino de aquel pathos y de aquel sentido de los valores que es íntimo a la palabra alma, como Sócrates la usa. Si nosotros destacamos que sus discursos exhortativos son la forma germinal de la diatriba de los filósofos populares de la edad helenística, y que ésta, por su parte, contribuyó a hacer nacer el ‘sermón' cristiano, no se trata sólo de indicar un pasaje y una continuidad en la forma literaria exterior. En este sentido ha trabajado ya mucho la filología tratando la relación entre estas formas y siguiendo cada uno de los motivos y los temas de la retórica de la persuasión a través de todo el desarrollo histórico. Se trata, mucho más, de afirmar que en la base de las tres fases del discurso exhortatorio hay una fe: ¿en qué beneficia al hombre conquistar todo el mundo, si pierde el alma? Justamente Adolfo Harnack, en su Esencia del Cristianismo, indicó como uno de los pilares de la religión de Jesús esta fe en el infinito valor del alma individual. Pero ésta había sido ya fundamento de la 'filosofía’ de Sócrates y de su esfuerzo educativo. Sócrates predica y convierte. Él llega a 'salvar la vida’ ${ }^{17}$

Y, en efecto, en el Protágoras, Platón pone en boca de Sócrates precisamente esta expresión: la filosofía en cuanto ciencia del arte de la medida

manifestando la verdad, haría adquirir al alma la tranquilidad, la consolidaría en la verdad y salvaría nuestra vida. ${ }^{18}$

Y lo confirma completamente, afirmando que la filosofía

${ }^{17}$ Jaeger, Paideia, vol. II, p. 64 s.

${ }^{18}$ Platón, Protagora, 356 E; Platone, Tutti gli scritti, op. cit. 
GIOVANNI REALE

es la ciencia de la que depende la salvación de la vida. ${ }^{19}$

Naturalmente, se trata de una ‘salvación’ de otra naturaleza respecto a la del mensaje cristiano, en cuanto se coloca en otro plano; sin embargo, aún en distinto plano, presenta algunas difícilmente contestables analogías con él.

El filósofo checo Jan Patocka (1907-77), en su libro Platón y Europa, de 1973 de cuya edición italiana yo me hice cargo, ${ }^{20}$ ha sostenido una tesis, en la que hay mucha verdad, según la cual precisamente en la adquisición de la concepción del ‘cuidado del alma' la conciencia de Europa ha empezado a construirse.

Recuerdo que Patocka se había opuesto en Praga al régimen comunista, con toda una serie de consecuencias, y con una muerte trágica tras un duro interrogatorio de la policía de Estado, ocurrido en 1977. Por su vida y su ejemplo ha sido llamado el Sócrates de Praga.

El cuidado del alma, dice él, es la formación interior del hombre, de una conciencia sólida e inquebrantable. Pero esto no es una forma de intelectualismo abstracto, es, por el contrario,

una aspiración a encarnar lo eterno en el tiempo y en el propio ser, una aspiración, al mismo tiempo, a resistir al huracán del tiempo, a resistir en todos los peligros que éste comporta, a resistir cuando el cuidado del alma pone al hombre en peligro. ${ }^{21}$

Cuando un hombre, en una comunidad, para cuidar el alma se pone fuera de las reglas de la sociedad es considerado un peligro para la sociedad misma. La misma existencia de Sócrates fue para la comuni-

${ }^{19}$ Cfr. Platón, Protagora, 356D-357 B.

${ }^{20}$ J. Patocka, Platone e l'Europa, 1977, prólogo e introducción de G. Reale, traducción de M. Cajthamla y G. Girgenti, Vita e Pensiero, Milán; de Patocka véase también Socrate. Lezioni di filosofia antica, Introducción de G. Girgenti, traducción de M. Cajthmla, texto checo para comparación, en la colección ‘Testi a fronte’, 1999, Milán, Rusconi Libri.

${ }^{21}$ Patocka, Platone e l'Europa, p. 116. 
dad una 'provocación', así como fue considerada una provocación por el régimen comunista la vida de Patocka.

Leamos su hermoso mensaje:

Sócrates es el primero que opone a la tiranía secreta, y a los revestimientos hipócritas de la antigua moral, la idea de que el hombre orientado en el sentido pleno del término, a la búsqueda de la verdad, el hombre que examina lo que es bueno, sin saber él mismo lo que es positivamente bueno, pero rechazando simplemente las falsas opiniones, parecerá necesariamente el peor y más nocivo de los hombres, mientras en realidad es el mejor, y, al contrario, quien adopta el comportamiento de la masa parecerá el mejor, mientras su esencia más profunda representa lo peor, y el conflicto inevitable entre estos dos sólo se concluirá con la ruina del hombre de bien. ${ }^{22}$

Pero Sócrates es el enviado de la divinidad, y, condenándolo, los mismos jueces se convierten en objeto de un juicio y de una condena divina. Sócrates, por tanto, deja, con su muerte, una herencia a los descendientes: no ayudándose a sí mismo ha ayudado a los otros. En otros términos: ha realizado en la mente de los descendientes el proyecto de una comunidad en la que pueda vivir el hombre que practica el 'cuidado del alma' en el sentido socrático. Precisamente de la tragedia de Sócrates nació el proyecto de la república ideal de Platón.

$\mathrm{Y}$ he aquí las consecuencias que Patocka elabora:

El adviento de la filosofía, su irrupción en la realidad, no significa de por sí que se haya convertido desde entonces en realidad en una fuerza directiva. O no ha sido nunca una fuerza directiva. La filosofía es la reflexión. Incluso después del despertar representado por la aparición de la reflexión, los hombres siguen rindiéndose al sueño, viven todavía en el mito. Platón lo sabe,

${ }^{22}$ Ibid., p. 117. 
GIOVANNI REALE

es una de las razones por las que crea a su vez mitos, nuevos mitos (pero existen razones más profundas). Mas el hecho es que, por la aparición de la filosofía, también la vida no filosófica se ve obligada de cualquier manera a hacer cuentas consigo misma, se ve obligada a reflexionar y, por este solo hecho, asimila algunos elementos de la filosofía. Esto ha determinado la especificidad de Europa: únicamente en Europa la filosofía ha nacido, en el sentido de este despertar, por el que el hombre se libera de la tradición para entrar en el presente del universo, únicamente en Europa, o, más precisamente, en esto que ha sido el germen de Europa: en Grecia. ${ }^{23}$

Para concluir este punto, reproducimos el pasaje en que Patocka lanza un mensaje de actualidad extraordinaria para el hombre de hoy, que intenta construir la nueva Europa:

Se habla interminablemente de Europa en el sentido político, pero se arrastra la cuestión de saber qué cosa sea realmente, y de dónde ha nacido. Nosotros queremos hablar de la unificación de Europa. Pero Europa ¿es algo que se puede unificar? ¿Se trata de un concepto geográfico o puramente político? No, y si queremos afrontar la cuestión de nuestra situación presente, debemos antes que nada comprender que Europa es un concepto que se basa en fundamentos espirituales, y entonces se comprende qué significa esta pregunta. ${ }^{24}$

Pero para hacer todavía más evidente el mensaje de Jan Patocka, cito un pasaje de Vaclav Havel, Presidente de la República Checa, publicado en La Repubblica del 23 de junio del 2000, que retoma y confirma análogos conceptos, tomados precisamente de Patocka, que fue un gran amigo suyo:

${ }^{23}$ Ibid., p. 38.

${ }^{24}$ Ibid., p. 117 s. 
Reflexionar sobre el europeismo significa investigar el conjunto de valores, ideales y principios que caracterizan a Europa. Esto conlleva, por definición, un examen crítico de aquel conjunto de ideas, a las que sigue la constatación de que muchas tradiciones, principios y valores europeos pueden resultar de doble filo. Algunos, exasperados o de alguna manera distorsionados, pueden conducirnos al infierno. En este esfuerzo de reflexión hay que poner el acento en la dimensión espiritual y en los valores que están en la base de la integración europea. Hasta hoy la unificación europea y su significado en el más amplio contexto de la civilización han estado ocultos tras cuestiones técnicas, económicas, financieras y administrativas.

La definición de una identidad europea no puede ser por tanto conquistada sino mediante una recuperación de valores espirituales, que proceden precisamente de aquel ‘cuidado del alma' de que hablaba Sócrates.

Un pasaje de Platón, sacado de Fedro, concluye la larga y profunda discusión sobre el modo de comunicar a los hombres los mensajes mediante los discursos (de los políticos, de los defensores en los procesos, los discursos públicos en general; hoy podríamos incluir en esta categoría, en gran medida, a los periodistas): el arte de los discursos debe mirar siempre no a lo 'verosímil' (a la apariencia de lo verdadero), sino a la 'verdad', cualquiera que sea el precio que tal elección pide.

He aquí el hermosísimo pasaje:

Aquellos que son más sabios que nosotros, dicen que quien posee inteligencia no debe ocuparse en complacer a los compañeros de esclavitud más que de modo lateral, sino mas a los amos que son buenos y que descienden de buenos. Por eso no te sorprenda que el camino a recorrer sea largo, pero, para llegar a grandes cosas, hay que recorrerlo (...). Por lo demás, como nos dice nuestro discurso, si uno lo desea, también estas cosas serán bellísimas, como consecuencia de aquéllas (...). 
GIOVANNI REALE

Para quien comienza cosas bellas es bello también sufrir, cualquier cosa que le toque. $^{25}$

El pasaje de Aristóteles, sacado de la Ética a Nicómaco, no es menos fuerte:

No hay que seguir a aquellos que aconsejan que, por ser hombres, se atienda a cosas humanas, y, siendo mortales, a cosas mortales, sino que en la medida en que sea posible, hay que hacerse inmortales y hacer todo lo posible para vivir según la parte más elevada de aquellas que se encuentran en nosotros; aunque sea pequeña en extensión, sobresale en mucho sobre todas las otras por potencia y valor. ${ }^{26}$

Pero el hombre moderno y contemporáneo está recorriendo un camino que acaba en precipicio, que, con Eliot, se puede describir así: las técnicas que hemos adquirido nos llevan a conocer cada vez más el 'movimiento', pero nos hacen olvidar el sentido de la 'inmovilidad'; la 'técnica del lenguaje' nos hace perder el sentido del 'silencio', y el conocimiento de las 'palabras' nos lleva a la ignorancia del 'Verbo'. Nuestros conocimientos nos llevan a la ignorancia, y, por tanto, nos acercan no a Dios, sino a la muerte; la ciencia nos ha hecho perder la antigua sabiduría, y la enorme difusión de la información con los varios medios nos hace perder la ciencia.

Leamos sus hermosísimos versos:

El ciclo interminable de la idea y de la acción, La invención infinita y el experimento infinito

Dan conocimiento del movimiento, no de la inmovilidad:

${ }^{25}$ Platón, Fedro, 273 E-274 B; traducción mía sacada de la edición que he publicado en la colección Lorenzo Valla de Mondadori, 1998, Milán, y contenida también en Platone, Tutti gli scritti, 2000, Milán, Bompiani.

${ }^{26}$ Aristóteles, Ética Nicomachea, VIII 7, 1177b-1178 a (traducción de A. Plebe). 
Conocimiento del lenguaje, pero no del silencio; Conocimiento de las palabras, e ignorancia del Verbo;

Todo nuestro conocimiento nos acerca más a la ignorancia, Toda nuestra ignorancia nos acerca más a la muerte.

Pero más cercanos a la muerte, no más cercanos a Dios. ¿Dónde está la vida que hemos perdido viviendo?

¿Dónde está la sabiduría que hemos perdido con el conocimiento?

¿Dónde está el conocimiento que hemos perdido en la información? ${ }^{27}$

(The endless cycle of idea and action, Endless invention, endless experiment, Brings knowledge of motion, but not of stillness;

Knowledge of speech, but not of silence;

Knowledge of words, and ignorance of the World.

All our knowledge brings us nearer to death, But nearness to death no nearer to GOD.

Where is the Life we have lost in living?

Where is the wisdom we have lost in knowledge?

Where is the knowledge we have lost in information?)

Pero como viático, para afrontar el duro camino que nos espera para recuperar aquellas raíces del futuro que están en el pasado, leamos estos espléndidos versos de Hölderlin:

Próximo está el Dios y difícil es aferrarlo.

Pero donde está el riesgo

también lo que salva crece. ${ }^{28}$

27 T.S. Eliot, Cori da "La Rocca”, 1, v. 6-16; (trad. de R. Sanesi con ligeros retoques en los dos versos finales), Opere, 1992, Milán, Bompiani, 2 vol., vol. I, p. 1231.

${ }^{28}$ F. Hölderlin, Patmo, v. 1-4 (trad. de E. Mandruzzato), Le liriche, 1993, Milán, Adelphi. 


\title{
GIOVANNI REALE
}

\author{
(Nab ist \\ Und schwer zu fassen der Gott. \\ Wo aber Gefahr ist, wachst \\ Das Rettende auch).
}

